\title{
Compulsive Alcohol Seeking Results from a Failure to Disengage Dorsolateral Striatal Control over Behavior
}

\author{
Chiara Giuliano, DDavid Belin, ${ }^{\star}$ and $®$ Barry J. Everitt ${ }^{\star}$ \\ Behavioural and Clinical Neuroscience Institute and Department of Psychology, University of Cambridge, Cambridge CB2 3EB, United Kingdom
}

The acquisition of drug, including alcohol, use is associated with activation of the mesolimbic dopamine system. However, over the course of drug exposure the control over drug seeking progressively devolves to anterior dorsal striatum (aDLS) dopamine-dependent mechanisms. The causal importance of this functional recruitment of aDLS in the switch from controlled to compulsive drug use in vulnerable individuals remains to be established. Here we tested the hypothesis that individual differences in the susceptibility to aDLS dopaminedependent control over alcohol seeking predicts and underlies the development of compulsive alcohol seeking. Male alcohol-preferring rats, the alcohol-preferring phenotype of which was confirmed in an intermittent two-bottle choice procedure, were implanted bilaterally with cannulae above the aDLS and trained instrumentally on a seeking-taking chained schedule of alcohol reinforcement until some individuals developed compulsive seeking behavior. The susceptibility to aDLS dopamine control over behavior was investigated before and after the development of compulsivity by measuring the extent to which bilateral aDLS infusions of the dopamine receptor antagonist $\alpha$-flupenthixol $(0,5,10$, and $15 \mu \mathrm{g} / \mathrm{side})$ decreased alcohol seeking at different stages of training, as follows: (1) after acquisition of instrumental taking responses for alcohol; (2) after alcohol-seeking behavior was well established; and (3) after the development of punishment-resistant alcohol seeking. Only alcohol-seeking, not alcohol-taking, responses became dependent on aDLS dopamine. Further, marked individual differences in the susceptibility of alcohol seeking to aDLS dopamine receptor blockade actually predicted the vulnerability to develop compulsive alcohol seeking, but only in subjects dependent on aDLS dopamine-dependent control.

Key words: addiction; alcohol; compulsivity; dopamine; seeking; striatum

\section{Significance Statement}

Over the course of addictive drug exposure, there is a transition in the control over drug seeking from ventral to anterior dorsal striatum (aDLS) dopamine-dependent mechanisms, but it is unclear whether this is causally involved in the development of compulsive drug seeking. We tested the hypothesis that individual differences in the reliance of alcohol seeking on aDLS dopamine predicts and underlies the emergence of compulsive alcohol seeking. We identified individual differences in the reliance of well established alcohol seeking, but not taking behavior, on aDLS mechanisms and also showed that this predicted the subsequent development of compulsive alcohol-seeking behavior. Thus, those individuals in whom alcohol seeking depended on aDLS mechanisms were vulnerable subsequently to display compulsivity.

\section{Introduction}

The transition from recreational to habitual and compulsive alcohol use is associated with a shift in the neural control over

Received Oct. 10, 2018; revised Nov. 29, 2018; accepted Dec. 19, 2018.

Author contributions: C.G., D.B., and B.J.E. designed research; C.G. performed research; C.G. and D.B. analyzed data; C.G., D.B., and B.J.E. wrote the paper.

The present study was funded by Medical Research Council Programme Grant MR/N02530X/1. The production of the P rats was funded by R24 Alcohol Research Resource Award Grant R24 AA015512 from the National Institute on Alcohol Abuse and Alcoholism. We thank Mickaël Puaud for assisting during surgeries, and Dr. Charles Goodlett, Dr. Larry Lumeng, Dr. Richard Bell, and Rebecca Jane Smith at the Indiana University School of Medicine for facilitating the provision of the selected lines of rats.

${ }^{*}$ D.B. and B.J.E. are co-last authors.

The authors declare no competing financial interests.

Correspondence should be addressed to Barry J. Everitt at bje10@cam.ac.uk. drug-seeking behavior from the ventral to the dorsolateral striatum (Vollstädt-Klein et al., 2010) that has been hypothesized to be causally involved in the development of addiction (Everitt and Robbins, 2005, 2016; Belin et al., 2013).

Thus, while the initial reinforcing and incentive motivational properties of addictive drugs are associated with activation of the mesolimbic system (Di Chiara and Imperato, 1988), cue-induced craving in humans addicted to drugs is associated with the activation of limbic cortical structures and the nucleus accumbens (NAc; Childress et al., 1999) and also increased dopamine (DA) transmission in the dorsal striatum (Volkow et al., 2006), the 


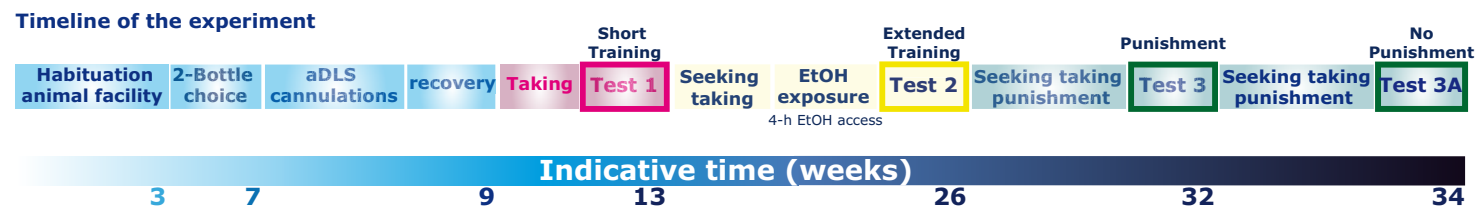

Figure 1. Timeline of the experiments. After 3 weeks of habituation to the animal facility followed by exposure to an intermittent two-bottle choice procedure for 12 sessions, P rats underwent cannula implantation bilaterally above the aDLS. After 1 week of recovery, rats were trained under a seeking-taking chained schedule of alcohol reinforcement and seeking responses challenged under probabilistic punishment to identify those that were vulnerable or resilient to developing compulsive alcohol seeking. Individual differences in the reliance of seeking and taking responses on aDLS dopamine-dependent mechanisms was assessed following bilateral infusion of the dopamine receptor antagonist $\alpha$-flupenthixol $(0,5,10$, or $15 \mu \mathrm{g} / \mathrm{side})$ at different stages of training: after acquisition of instrumental responding for alcohol (Test 1), after protracted exposure to the seeking-taking chained schedule of reinforcement (Test 2), when seeking performance was measured under the threat of punishment (Test 3), or under extinction following several baseline sessions after the termination of punishment (Test 3A).

activation of which both correlates with the severity of addiction and is the best predictor of subsequent drug use or relapse $(\mathrm{Ga}-$ ravan et al., 2000; David et al., 2005; Volkow et al., 2006; Boileau et al., 2007; Zijlstra et al., 2009; Vollstädt-Klein et al., 2010).

These observations align with data from animal studies (for review, see Everitt and Robbins, 2005; Belin et al., 2013). In primates, alterations in glucose metabolism and the levels of expression of molecular markers of dopamine transmission (Letchworth et al., 2001; Porrino et al., 2004, 2007) occur initially in the NAc but progressively encompass the more dorsal and lateral parts of the caudate and putamen over a longer history of drug self-administration. Similar alterations in dopamine markers were observed to spread from the ventral to the anterior dorsolateral striatum (aDLS) in rats over the course of $50 \mathrm{~d}$ of cocaine self-administration (Besson et al., 2013). This parallels behavioral data showing that cocaine-seeking behavior becomes associated with (Ito et al., 2002; Willuhn et al., 2012) and dependent on the aDLS when well established (Vanderschuren et al., 2005; Belin and Everitt, 2008; Zapata et al., 2010; Murray et al., 2014, 2015). Functional recruitment of the aDLS over prolonged histories of drug exposure has also been demonstrated in rats trained to seek heroin (Hodebourg et al., 2018) and alcohol (Corbit et al., 2012; Spoelder et al., 2017).

This engagement of the dorsal striatum is seen in animals seeking stimulants, heroin, and alcohol before the onset of compulsivity and in humans before a diagnosis of addiction according to Diagnostic and Statistical Manual of Mental Disorders IV criteria (Vollstädt-Klein et al., 2010; Cox et al., 2017). However, our hypothesis (Everitt and Robbins, 2005, 2016) that the engagement of dorsal striatal mechanisms is causally required for the development of compulsive drug seeking has not been directly tested, despite claims to have done so (Singer et al., 2018). Here we investigated whether individuals vulnerable to the development of compulsivity are those in which alcohol-seeking behavior had become reliant on aDLS dopaminergic processes.

We therefore trained alcohol-preferring $(\mathrm{P})$ rats (Bell et al., 2006) under a seeking-taking chained schedule of alcohol reinforcement and then introduced probabilistic punishment of the seeking, and not the taking, responses to assess the development of punishment-resistant, compulsive alcohol seeking. Infusions of the dopamine receptor antagonist $\alpha$-flupenthixol via cannulae bilaterally targeting the aDLS were then made at different time points over the course of training to measure the reliance of alcohol seeking on aDLS dopamine, before and after the development of compulsivity.

The reliance of alcohol seeking on aDLS dopamine progressively emerged in only some individuals and predicted the vulnerability subsequently to develop compulsive alcohol seeking, therefore providing evidence that it stems from an inability to disengage aDLS control over seeking behavior.

\section{Materials and Methods}

\section{Animals}

Male P rats $(\sim 30 \mathrm{~d}$ old, $n=40)$ obtained from Indiana University Medical Center (Indianapolis, IN) were group housed during 3 weeks of habituation in the animal facility, and then single housed under a reversed $12 \mathrm{~h}$ light/dark cycle (lights off at 7:00 A.M.) with food and water always available ad libitum. Experiments were performed every other day between 8:30 A.M. and 4:00 P.M. and were conducted in accordance with the UK (1986) Animal (Scientific Procedures) Act (Project license 70/ 7548). Twenty-six rats completed the full experiment, and the intracerebral cannulae of others failed at some point during the lengthy experiment. The number of rats that completed each test is reported accordingly.

\section{Drugs}

Ethanol (EtOH) solutions were prepared by mixing 99.8\% EtOH (Sigma-Aldrich UK) in tap water to obtain $10 \% \mathrm{EtOH}(\mathrm{v} / \mathrm{v}$; two-bottle choice procedure) or $15 \% \mathrm{EtOH}(\mathrm{v} / \mathrm{v}$; instrumental conditioning), as previously described (Giuliano et al., 2018).

The dopamine receptor antagonist $\alpha$-flupenthixol (Sigma-Aldrich UK) was dissolved in double-distilled water. Drug doses (5, 10, or 15 $\mu \mathrm{g} / \mathrm{side}$ ) are reported in the salt form, as previously described (Murray et al., 2015).

\section{Surgery: aDLS cannulations}

Rats underwent standard intrastriatal cannula implantation under general anesthesia (isoflurane, $5 \%$ induction/2\% maintenance). Guide cannulae (22 gauge; Plastics One) were bilaterally implanted $2 \mathrm{~mm}$ above the anterior dorsolateral striatum [anterior/posterior $(\mathrm{AP})+1.2$, mediolateral (ML) \pm 3 , dorsal/ventral (DV) -2 ; AP and ML coordinates measured from bregma, DV coordinates from the dura, incisor bar at -3.3 $\mathrm{mm}$ ], as previously described (Murray et al., 2014). Cannulae were held in place using dental acrylic cement anchored to four stainless steel screws tapped into the frontal and parietal bones of the skull. Obturators (Plastics One) were placed in the cannulae to maintain patency. Rats were treated daily for $5 \mathrm{~d}$ after surgery with $1 \mathrm{mg} / \mathrm{kg}$ anti-inflammatory drug Metacam (Boehringer Ingelheim) orally administered.

\section{Apparatus}

Behavioral training was conducted in 12 operant chambers (Med Associates) as previously described (Giuliano et al., 2018). Each chamber was enclosed within a sound-attenuating box containing a fan, which also helped to eliminate extraneous background noise, and was equipped with two retractable levers $(4 \mathrm{~cm}$ wide, $12 \mathrm{~cm}$ apart, and $8 \mathrm{~cm}$ from the grid floor), a cue light $(2.5 \mathrm{~W}, 24 \mathrm{~V})$ above each lever, a receptacle connected with a $10 \mathrm{ml}$ syringe containing $15 \% \mathrm{EtOH}$ and in turn connected with a dipper, and a white house light $(2.5 \mathrm{~W}, 24 \mathrm{~V})$ positioned at the back of the chamber, opposite the levers. Lever presses, light stimulus presentation, reward delivery, and data collection were controlled by a computer running Whisker control software (Cardinal and Aitken, 2010).

\section{Procedures}

The series of experiments conducted in this study is schematically summarized in Figure 1. 


\section{Two-bottle choice}

Animals were presented in their home cage with intermittent concurrent access to one bottle of $10 \% \mathrm{EtOH}(\mathrm{v} / \mathrm{v})$ and one bottle of water for a total of 12 sessions. The bottles were weighed once a day at the same time, and voluntary consumption of the two liquids was assessed every $24 \mathrm{~h}$. The bottle position was changed daily to avoid any side preference. The volume consumed in each session was calculated as the weight difference between the start and the end of the sessions, minus 1.5 and $1 \mathrm{~g}$, respectively, for spillage for $\mathrm{EtOH}$ and water, accounted for by subtracting the volume of fluid lost from bottles in an empty cage. Alcohol intake $(\mathrm{g} / \mathrm{kg})$ and the percentage of alcohol preference over the total fluid intake (\%) were assessed every $24 \mathrm{~h}$.

\section{Assessment of individual variability in the reliance on aDLS dopamine-dependent mechanisms in the control over alcohol seeking and taking over the course of the development of compulsive alcohol-seeking behavior}

Seven days after aDLS cannulation, rats were trained instrumentally on a seeking-taking-punishment procedure until some individuals eventually developed compulsive seeking behavior. The full training consisted of the following five phases, as previously described (Giuliano et al., 2018):

Pavlovian conditioning (phase I). Rats were initially trained to associate a light stimulus presentation with the opportunity to drink 15\% EtOH: a $20 \mathrm{~s}$ light conditioned stimulus (CS) was illuminated during the delivery of $0.1 \mathrm{ml}$ of $15 \% \mathrm{EtOH}(\mathrm{v} / \mathrm{v})$ in the receptacle between the two levers.

Taking phase (phase II). Each seeking-taking cycle in the chained schedule of alcohol reinforcement began with the insertion of the randomly assigned taking lever. Rats were trained to press the taking lever under a fixed ratio (FR) 1 (FR:1) schedule of reinforcement (FR1), which resulted in $5 \mathrm{~s}$ of CS illumination, extinction of the house light, and delivery of $0.1 \mathrm{ml}$ of $15 \% \mathrm{EtOH}$. Rats were limited to a maximum of 45 rewards/2 h session.

Seeking-taking phase (phase III). Each cycle of the seeking-taking chained schedule began with insertion of the seeking lever (at a location distinct from the taking lever that was retracted). Seeking lever presses under a random interval (RI) schedule were never directly reinforced, but instead resulted in the extension of the taking lever and the simultaneous retraction of the seeking lever. Taking lever responses under FR1 resulted in the illumination of the stimulus light above the taking lever for $5 \mathrm{~s}$, the delivery of $0.1 \mathrm{ml}$ of $15 \% \mathrm{EtOH}$, and a time-out of $2 \mathrm{~min}$, in which both levers were retracted. Rats were initially trained to press the seeking lever progressively under an RI of $5 \mathrm{~s}$ (RI5), $15 \mathrm{~s}$ (RI15), $30 \mathrm{~s}$ (RI30), and $60 \mathrm{~s}$ (RI60), with increments occurring after two consecutive sessions under each RI schedule.

Free alcohol exposure (phase IV). Because the interaction between the degree of exposure to drugs and vulnerability in exposed individuals has been shown to influence the vulnerability to persist in responding for a drug despite the risk of punishment (Pelloux et al., 2007), rats underwent eight sessions with $4 \mathrm{~h}$ access to a $15 \% \mathrm{EtOH}$ bottle in the home cage. Alcohol intake (in grams per kilogram) was assessed for $4 \mathrm{~h}$.

Eight additional seeking-taking chained schedule sessions under RI60 were interspersed between the alcohol exposure sessions. During the last two sessions under RI60, rats were limited to a maximum of 25 seekingtaking response cycles/2 $\mathrm{h}$ session to establish a baseline level before test 2 and the subsequent introduction of the probabilistic punishment contingency wherein the proportion of rewarded and punished trials was kept constant across 25 cycles of the chained schedule of reinforcement.

Seeking-taking-punishment phase (phase V). Each cycle began exactly as described for the seeking-taking phase. However, during each punishment session, mild footshocks were randomly administered on completion of $30 \%$ of the cycles: 17 of the 25 total cycles were reinforced by delivery of $0.1 \mathrm{ml}$ of $15 \% \mathrm{EtOH}$ following a taking lever response, whereas in 8 of the 25 cycles, seeking responses were randomly punished by a $0.25-0.45 \mathrm{~mA}, 0.5 \mathrm{~s}$ footshock. The taking lever was never presented if the seeking component of the chain resulted in punishment (so that punishment was never associated with the reinforcer). Although the seeking responses were randomly punished during a session, the first seeking-taking cycle of the session was always reinforced, and no more than two consecutive seeking-taking cycles were punished. The intensity of the shock was progressively increased over daily sessions from 0.25 to $0.45 \mathrm{~mA}$ in $0.5 \mathrm{~mA}$ increments, before stabilizing at $0.45 \mathrm{~mA}$ for six consecutive daily sessions.

\section{Intrastriatal infusions}

The influence of aDLS dopamine receptor blockade on alcohol seeking and taking was tested at the following three time points of the training: (1) after the acquisition of instrumental taking responses for alcohol (Test 1 , on completion of phase II of instrumental training); (2) when alcohol-seeking was well established (Test 2, on completion of phase IV of instrumental training); and (3) when alcohol-seeking persisted despite punishment in vulnerable individuals (Test 3 , on completion of phase $\mathrm{V}$ of instrumental training). On completion of Test 3 , rats were rebaselined under a seeking-taking-punishment schedule and were tested in extinction on the seeking lever alone to measure the motivation for alcohol independent of alcohol delivery and consumption (Test 3A).

Experimentally, Test 1 consisted of 45 rewards/ $2 \mathrm{~h}$ session under FR1 on the taking lever only. Test 2 consisted of 25 seeking-taking cycles $/ 2 \mathrm{~h}$ session under the seeking-taking chained schedule, whereas Test 3 consisted of 25 cycles/2 h session under the seeking-taking-punishment schedule. Finally, Test 3A consisted of a 15 min session of responding on the seeking lever only, in extinction (no alcohol was available).

Pharmacologically, Tests $1,2,3$, and $3 \mathrm{~A}$ were preceded by intra-aDLS infusions ( $0.5 \mu \mathrm{l} / \mathrm{side})$ of $\alpha$-flupenthixol $(0,5,10$, or $15 \mu \mathrm{g} /$ side for Tests $1,2,3$, and $0,10 \mu \mathrm{g} /$ side for Test $3 \mathrm{~A}$, administered in a counterbalanced order following a Latin-Square design), made via 28 gauge steel cannulae (Plastics One) lowered to the injection sites $2 \mathrm{~mm}$ ventral to the end of the guide cannulae (i.e., DLS, $5 \mathrm{~mm}$ ). Infusions were made over $90 \mathrm{~s}$ using a syringe pump (Harvard Apparatus) and were followed by a $60 \mathrm{~s}$ period to allow diffusion of the infused drug or vehicle before injectors were removed and obturators were replaced. Test sessions began $5 \mathrm{~min}$ later. Each infusion day was followed by a day off and a rebaseline session under the specific conditions of the task that was being tested.

\section{Histology}

At the end of the experiment, rats were killed with an overdose of sodium pentobarbital (300 mg; Dolethal, Vetoquinol) then perfused transcardially with isotonic saline followed by $10 \%$ neutral buffered formalin. Brains were extracted and transferred to a $20 \%$ sucrose solution in $0.01 \mathrm{M}$ PBS for $\sim 24 \mathrm{~h}$ before sectioning at $60 \mu \mathrm{m}$ using a Leica CM3050 S Research Cryostat. Slices were mounted and stained with Cresyl Violet. Cannulae placements in the aDLS were verified using a light microscope.

\section{Data and Statistical analyses}

Data are presented as the mean \pm SEM and individual data points. Data were analyzed at both the population (dimensional analyses) and subpopulation (between-subject/within-subject comparisons) levels using SPSS version 21 (IBM).

Assumptions for homogeneity of variance and normal distribution of the datasets were tested using the Levene's and Kolmogorov-Smirnov tests, respectively.

Two two-step K-mean cluster analyses were performed to identify specific individuals' subpopulations: (1) reliance on aDLS DA-dependent mechanisms was assessed by analyzing the percentage reduction of lever-pressing responses from baseline (i.e., the vehicle treatment, with responses normalized to $100 \%$ and the lever presses at each drug dose expressed as a percentage reduction from this vehicle-treated baseline) following bilateral intra-aDLS infusions of $\alpha$-flupenthixol during Test 2; three subpopulations of rats were identified based on the magnitude of the disruption of alcohol seeking by aDLS dopamine receptor blockade [susceptible (S), intermediate (I), and nonsusceptible (NS)]; and (2) punishment-resistant seeking behavior was assessed by analyzing the number of completed seeking-taking cycles during the last $3 \mathrm{~d}$ of the seeking-taking-punishment chained schedule (footshock intensity, 0.45 $\mathrm{mA}$; three data points per rat were considered), thereby enabling compulsive (C), intermediate (I) and noncompulsive (NC) animals to be identified, as previously described (Giuliano et al., 2018). C, I, and NC animals were identified only at the end of the training under seekingtaking-punishment task, but all of the related data were retrospectively 
analyzed and are represented according to that final classification. The number of completed seeking-taking cycles per session was considered the best indicator of performance in light of the fact that under the seeking-taking-punishment chained schedule of reinforcement the opportunity to express a taking response (under FR1) is dependent on the successful completion of the behavioral sequence on the seeking lever (under RI60; see Pelloux et al., 2007).

Between-group comparisons were performed using repeated-measures ANOVA with dose as a within-subject factor and compulsivity as the between-subject factor. Data from each test were analyzed separately as follows: (1) four levels, when the seeking or taking lever presses were analyzed at each dose tested; (2) three levels, when the percentage changes from vehicle were analyzed for each dose tested; and (3) two levels, when the data from Test $3 \mathrm{~A}$ were analyzed, with dose as the withinsubject factor and compulsivity as the between-subject factor. When comparing the effects of $5 \mu \mathrm{g} / \alpha$-flupenthixol into the aDLS as percentage changes from vehicle at Tests 2 and 3 , the factor 'shock' ( 2 levels, no shock under Test 2 and shock under Test 3 ) was added. Two-tailed values of $p \leq$ 0.05 were considered statistically significant. Significant main effects and interactions were analyzed further using the Sidak's post hoc test or contrast analysis for planned comparisons, where appropriate. All partial $\eta^{2}$ measures of effect size $\left(\mathrm{p} \eta^{2}\right)$ are reported, as previously described (Daniel et al., 2017).

Pearson correlations were calculated for seeking responses at the dose of $5 \mu \mathrm{g} /$ infusion (expressed as the percentage reduction from baseline) and the number of completed seeking-taking cycles during the last $3 \mathrm{~d}$ of the seeking-taking-punishment schedule to test at the dimensional level the hypothesis that individual variability in the reliance on aDLS DAdependent mechanisms in the control of alcohol seeking predicts the development of compulsivity.

\section{Results}

\section{Reliance on DLS dopaminergic mechanisms in well established alcohol seeking predicts the vulnerability to compulsivity}

Twenty-six rats with cannula placements located in the aDLS (Fig. 2A, cannula placements) completed the entire experiment. Early instrumental performance for $10 \%$ alcohol under continuous reinforcement was completely unaffected by aDLS dopamine receptor blockade (dose: $F_{(3,75)}=1.53, p=$ not significant, $\mathrm{p} \eta^{2}=0.06$; Fig. $2 A$ ), thereby demonstrating that instrumental responding is initially underpinned by an aDLS-independent neural network, as previously described (Corbit et al., 2012; Spoelder et al., 2017). However, when instrumental seeking and taking responses were spatially and temporally dissociated, as measured under the seeking-taking schedule of reinforcement (Giuliano et al., 2018), alcohol seeking, but not taking, was decreased by aDLS dopamine receptor blockade. Thus, instrumental responses on the seeking lever, but not the taking lever, were dose-dependently decreased by bilateral aDLS dopamine receptor blockade (main effect of lever: $F_{(1,50)}=92.69, p<$ $0.001, \mathrm{p} \eta^{2}=0.65$; dose: $F_{(3,150)}=12.96, p<0.001, \mathrm{p} \eta^{2}=$ 0.21 ; lever $\times$ dose interaction: $F_{(3,150)}=12.69, p<0.001, \mathrm{p}^{2}=$ 0.20 ; Sidak's post hoc comparisons: vehicle vs 5,10 , and $15 \mu \mathrm{g} /$ infusion, $p=0.008, p<0.001$, and $p<0.001$, respectively; Fig. $2 C, D)$. These data therefore demonstrate that in a chained schedule of reinforcement the responses distal to reinforcement (seeking responses), but not proximal to the consummatory act of drinking (taking responses), became dependent on aDLS dopaminergic mechanisms.

However, that observation at the population level falls short of explaining any potential causal importance of this transition to aDLS dopamine-dependent control over behavior to the subsequent emergence of compulsive (punishment-resistant) alcohol seeking that occurs only in a subset of vulnerable individuals exposed to alcohol (Anthony et al., 1994). Hence, we investigated, at the individual level, the variability in the reliance of alcohol-seeking responses on aDLS dopamine-dependent mechanisms. We first established that the susceptibility to aDLS dopamine receptor blockade was variable across subjects regardless of baseline levels of responding, as represented by the normalized reduction in alcohol-seeking responses by intra-aDLS infusions of $\alpha$-flupenthixol at Test 2 (Fig. $2 E$ ). We then subjected these data to a K-mean cluster analysis that revealed three distinct subpopulations (Fig. $2 F, G$; main effect of group: $F_{(2,23)}=50.33, p=$ $0.0001, \mathrm{p} \eta^{2}=0.81$; and group $\times$ dose interaction: $F_{(4,46)}=3.38$, $\left.p=0.02, \mathrm{p} \eta^{2}=0.23\right)$. Ten rats, representing $39 \%$ of the population, were highly susceptible to aDLS dopamine receptor blockade (S rats), in that their seeking responses were greatly decreased, whereas in 5 rats, or $19 \%$ or the population, alcoholseeking behavior was unaffected by the same manipulation (NS rats; Fig. $2 F, G$ ). The third subpopulation of 11 rats, representing $42 \%$ of the overall population, were deemed intermediate (I) rats because they only partially suppressed their alcohol-seeking responses following bilateral infusions of $\alpha$-flupenthixol in the aDLS (Fig. 2F, G).

The subsequent introduction of the probabilistic punishment contingency on seeking lever press responses revealed that those rats in which alcohol seeking at Test 2 was heavily reliant on aDLS DA were more likely to persist in seeking alcohol despite the risk of punishment (Fig. 2H). Although punishment resulted in an intensity-dependent decrease in alcohol seeking at the population level (Fig. 3A; main effect of sessions: $F_{(9,225)}=36.98, p<$ $0.001, \mathrm{p} \eta^{2}=0.60$ ), the three subpopulations (S, I, and NS) that were identified according to the reliance of their alcohol-seeking responses on aDLS dopamine displayed marked differences in their response to punishment over time (main effect of sessions: $F_{(9,207)}=36.24, p<0.001, \mathrm{p} \eta^{2}=0.61$; session $\times$ group interaction: $\left.F_{(18,207)}=1.74, p=0.03, \mathrm{p} \eta^{2}=1.13\right)$. Thus, aDLS $\alpha$-flupenthixol-S rats displayed higher levels of responding under punishment than I and NS rats [S vs NS rats, $p=0.028$ (planned comparison); S vs I rats, $\mathrm{p}=$ not significant; Fig. $2 \mathrm{H}$ ]. These data suggest that the degree to which alcohol seeking depends on aDLS dopamine-dependent mechanisms predicts an increased propensity for subsequent showing of compulsive (i.e., punishmentresistant) alcohol-seeking behavior. This was further supported at the dimensional level by the evidence that reliance of baseline seeking behavior on aDLS dopamine is linearly related to the persistence of alcohol seeking under punishment measured subsequently (Pearson's correlation, $r=-0.378 ; p=0.028 ; n=26$; Fig. 2I).

\section{Compulsive alcohol seeking is mediated by aDLS dopamine-dependent mechanisms}

Having established that the individual variability in the degree of reliance of alcohol seeking on aDLS dopamine predicts an increased vulnerability to show compulsive alcohol seeking, we sought to test the hypothesis that compulsivity actually reflects an inability to disengage this aDLS dopamine-dependent mechanism when alcohol seeking is punished. Thus, the 26 rats subjected to punishment that decreased responding overall (main effect of session: $F_{(9,225)}=36.98, p<0.001, \mathrm{p} \eta^{2}=0.60$; Fig. $3 A$ ), were stratified according to their compulsive, punishmentresistant, alcohol-seeking phenotype, as previously described (Giuliano et al., 2018). A K-mean cluster analysis performed on the completed cycles during the last three sessions of punishment (Fig. 3B) identified three highly distinct subpopulations (main effect of group: $F_{(2,23)}=107.24, p<0.001, \mathrm{p} \eta^{2}=0.90$; session: 
A

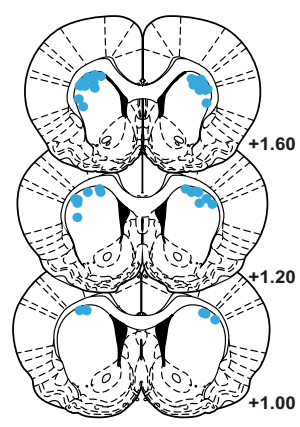

B

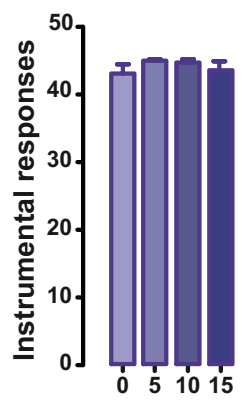

[ $\alpha$-flupenthixol]
C

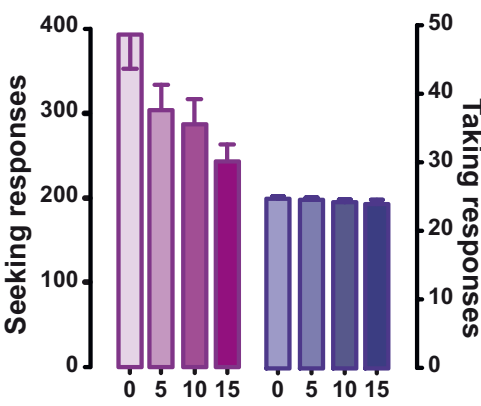

[ $\alpha$-flupenthixol] ( $\mu \mathrm{g} /$ side)

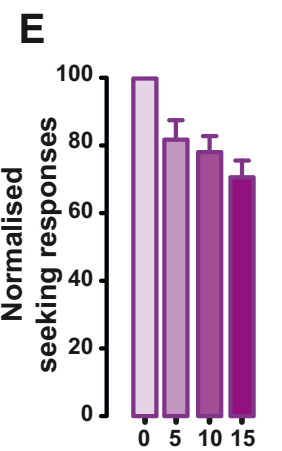

[ $\alpha$-flupenthixol]

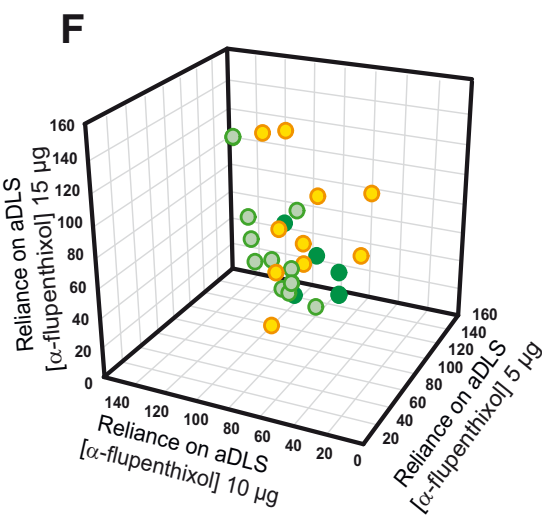

|

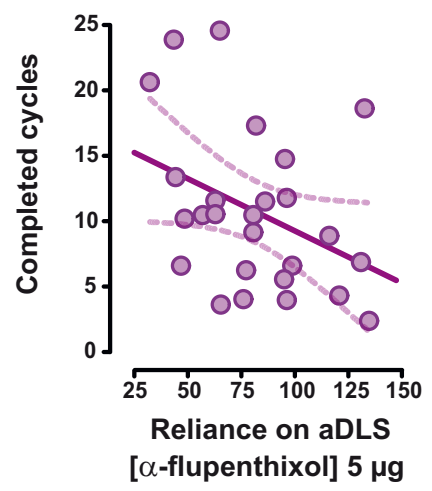

G

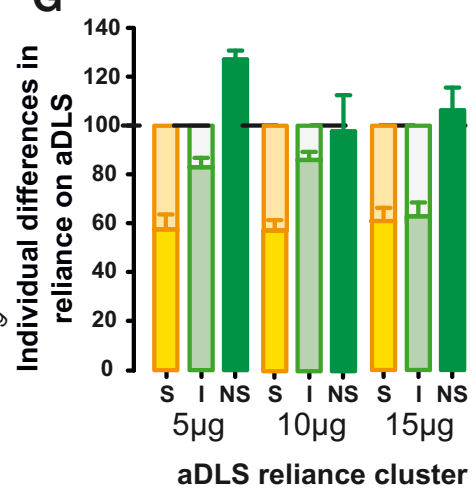

H

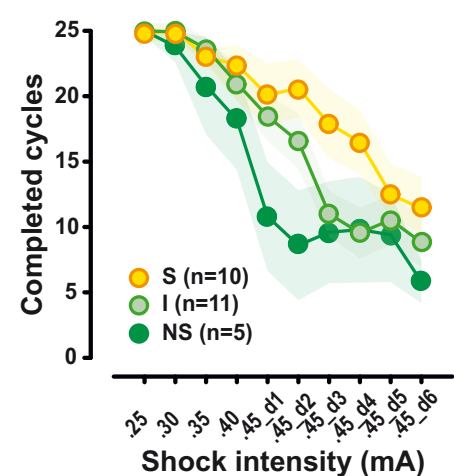

Figure 2. Reliance on aDLS dopaminergic mechanisms of well established alcohol seeking predicts the vulnerability to compulsivity. $A$, The 26 rats included in the study all had injection sites (blue dots) located within the aDLS as verified by histological assessment of coronal sections from +1.6 to $+1.0 \mathrm{~mm}$ anteroposterior from bregma. $\boldsymbol{B}$, Early instrumental performance for $10 \%$ EtOH (purple bars) was unaffected by aDLS dopamine receptor blockade with $\alpha$-flupenthixol $(0,5,10$, or $15 \mu \mathrm{g} / \mathrm{side}, n=26)$. $C$, $\boldsymbol{D}$, With the progression of training, while taking responses were never affected by aDLS dopamine receptor blockade ( $\boldsymbol{D}$, purple bars, on the right), seeking responses were dose-dependently decreased by bilateral aDLS infusions of the dopamine receptor antagonist $\alpha$-flupenthixol $(0,5,10$, or $15 \mu \mathrm{g} / \mathrm{side}, n=26$; $\boldsymbol{C}$, fuchsia bars, on the left). $\boldsymbol{E}$, Marked individual differences in the susceptibility of alcohol-seeking responses to aDLS dopamine were revealed when normalizing the influence of aDLS dopamine receptor blockade on seeking responses relative to baseline performance (i.e., the vehicle-treated rats were considered our controls, and their responses were normalized to $100 \%$, whereas the lever presses at each dose tested were then expressed as percentage changes from vehicle). $\boldsymbol{F}, \mathbf{G}, \mathrm{A}$ cluster analysis segregated rats that were highly susceptible to ( $\mathrm{rats}, n=10$; yellow), not affected by (NS rats, $n=5$; green), and minimally affected by (I rats, $n=11$; light green) aDLS dopamine receptor blockade. $\boldsymbol{H}$, The susceptibility of alcohol seeking to aDLS dopamine predicted the vulnerability to subsequent development of compulsive alcohol seeking, as shown by the higher number of completed seeking-taking cycles per session under probabilistic punishment displayed by $S$ rats $(n=10$; yellow) compared with both NS rats $(n=5$; green) and I rats ( $n=11$; light green). $I$, The relationship between susceptibility to aDLS dopamine receptor blockade and the emergence of compulsive alcohol seeking was further supported by dimensional analysis (Pearson's correlation). Graphs show the mean \pm SEM.

$F_{(2,46)}=4.16, p=0.022, \mathrm{p}^{2}=0.15 ;$ group $\times$ session interaction: $F_{(4,46)}=0.70, \mathrm{~ns}, \mathrm{p} \eta^{2}=0.06$; Sidak's post hoc comparisons: $\mathrm{C}$ vs I and NC, $p<0.001$ in each comparison). Five rats displayed alcohol seeking that was completely resistant to punishment (i.e., compulsive), while 11 rats showed a marked decrease in alcohol seeking and were therefore considered noncompulsive. The remaining 11 rats responded under punishment at intermediate levels. Both the incidence and the qualitative nature of these groups were similar to those previously described using a similar procedure (Giuliano et al., 2018; Fig. 3C).
A retrospective analysis of the susceptibility of each of the three subgroups to aDLS dopamine receptor blockade revealed that alcohol seeking under baseline conditions was equally dependent on aDLS dopamine transmission in $\mathrm{C}, \mathrm{I}$, and $\mathrm{NC}$ rats (main effect of dose: $F_{(3,69)}=10.63, p=0.001, \mathrm{p} \eta^{2}=0.32$; Sidak's post hoc comparisons: vehicle vs 5,10 , and $15 \mu \mathrm{g} /$ infusion, $p<0.05, p<0.01$ and $p<0.001$, respectively; compulsivity: $F_{(2,23)}=0.27, p=$ not significant; and dose $\times$ compulsivity interaction: $F_{(6,69)}=1.19, p=$ not significant; Fig. $\left.3 D\right)$. However, the identical intra-aDLS manipulation performed when the rats 
A

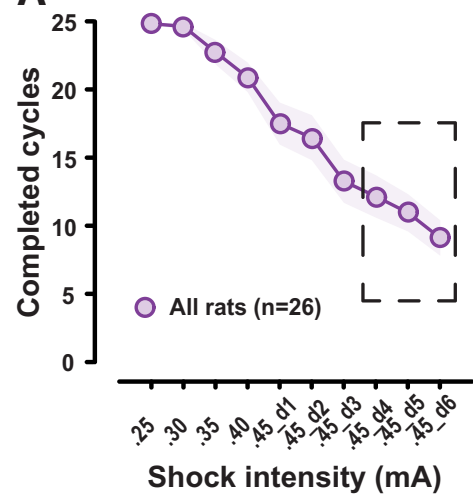

D

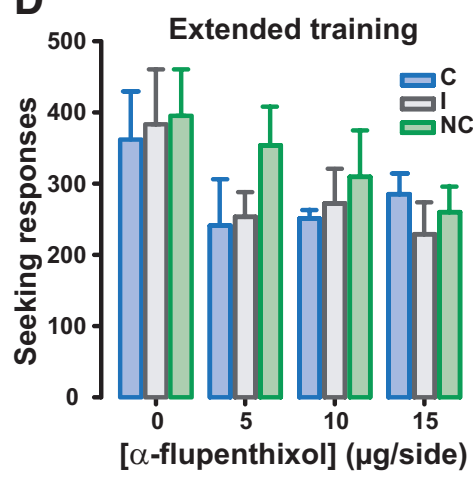

B

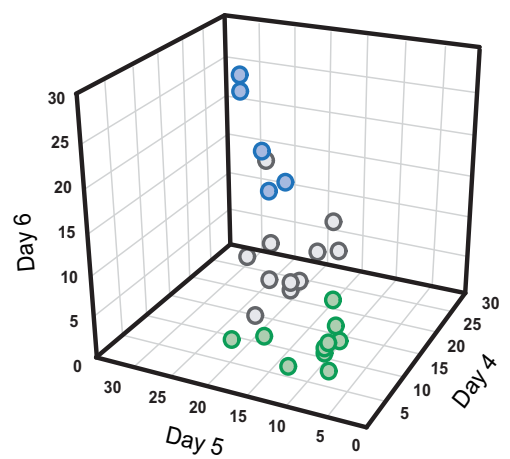

E

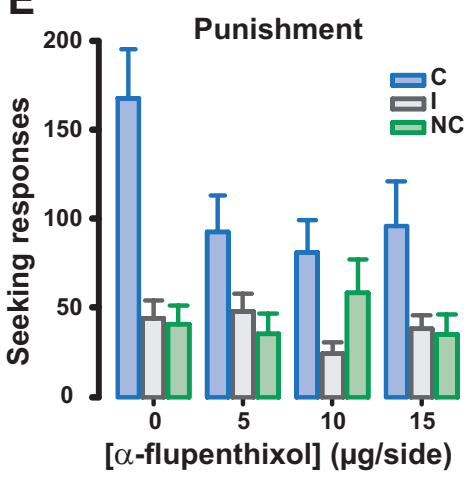

C

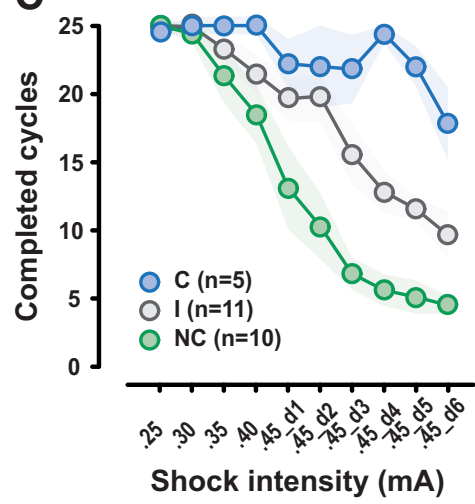

F

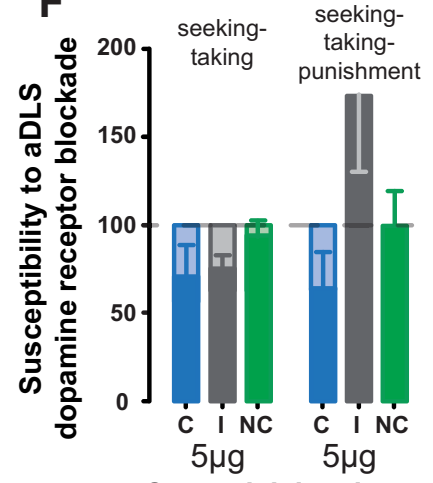

Compulsivity cluster
G

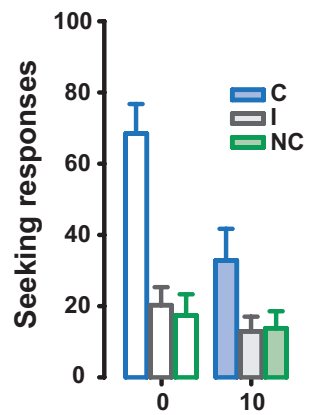

[ $\alpha$-flupenthixol] $(\mu \mathrm{g} / \mathrm{side})$

H

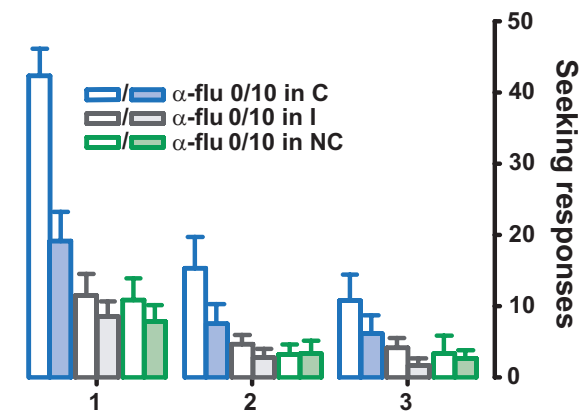

Figure 3. Compulsive alcohol seeking is mediated by aDLS dopamine-dependent mechanisms. $A$, Introduction of unpredictable punishment of seeking responses (footshock intensity increasing from 0.25 to $0.45 \mathrm{~mA}$ ) over repeated sessions resulted in decreased alcohol-seeking responses in the entire population of rats $(n=26)$ as revealed by the magnitude and time-dependent decrease in the number of completed seeking-taking cycles per $2 \mathrm{~h}$ session. $\boldsymbol{B}, \boldsymbol{C}$, However, marked interindividual differences in the response to punishment of seeking responses were revealed by a cluster analysis performed on the completed cycles during the last three sessions of punishment (in the dashed-line rectangle) in that 5 rats resisted punishment and were deemed $C$ (blue dots), 15 rats were sensitive to punishment and were deemed NC (green dots), and 11 rats displayed intermediate sensitivity to punishment (I; gray dots). D, E, While seeking responses after extended training were, at the population level, dose-dependently decreased by bilateral aDLS infusions of the dopamine receptor antagonist $\alpha$-flupenthixol $(0,5,10$, or $15 \mu \mathrm{g} /$ side) in all of the rats regardless of their compulsive phenotype ( $\mathrm{rats}$ in blue, I rats in gray, and NC rats in green; $\boldsymbol{D})$, only C rats displayed a susceptibility to aDLS dopamine receptor blockade when instrumental seeking responses were performed under the threat of punishment $(\boldsymbol{E})$. $\boldsymbol{F}$, The selective effect of aDLS dopamine receptor blockade in $\mathrm{C}$ rats cannot be attributable to rate dependency, as demonstrated by the lack of difference in the effect of the otherwise effective dose of $5 \mu \mathrm{g} /$ side $\alpha$-flupenthixol infusion on the normalized seeking responses of $\mathrm{C}$ rats $(n=5$; blue) tested under the seeking-taking task (on the left) and under the seeking-taking-punishment task (on the right), compared with I rats ( $n=11$; gray) and NC rats ( $n=15$; green). $\boldsymbol{G}, \boldsymbol{H}$, The differential susceptibility to aDLS dopamine receptor blockade that emerged in C rats under punishment persisted after its cessation, in that only C rats maintained alcohol-seeking responses that were susceptible to bilateral aDLS $\alpha$-flupenthixol (10 $\mu \mathrm{g} /$ side) infusions measured over 15 min extinction sessions that followed several nonpunished baseline sessions ( $G$ ), with the differences among $C$ rats $(n=5$; blue), I rats ( $n=11$; gray), and NC rats $(n=15$; green) being observable at each 5 min block of the extinction session $(\boldsymbol{H})$. Graphs show mean \pm SEM values.

were tested under the threat of punishment (Test 3) revealed a compulsivity-dependent effect in that it selectively reduced the seeking responses only of compulsive rats (main effect of dose: $F_{(3,69)}=4.49, p=0.007, \mathrm{p} \eta^{2}=0.16 ;$ compulsivity: $F_{(2,23)}=$ $12.26, p<0.001 ; \mathrm{p} \eta^{2}=0.52$; dose $\times$ compulsivity interaction: $\left.F_{(6,69)}=4.10, p=0.002, \mathrm{p} \eta^{2}=0.26\right)$. Post hoc analyses revealed that $\mathrm{C}$ rats, in which responses were higher than those displayed by NC rats $(p<0.001)$ and I rats $(p<0.001)$ after vehicle infusions, showed a clear decrease in responding at the highest dose of $\alpha$-flupenthixol ( $15 \mu \mathrm{g} / \mathrm{side}$ ) compared with vehicle.

These data suggest that if I and NC rats had engaged their aDLS at baseline, they were very likely to disengage it in the face of punishment, whereas, in marked contrast, $\mathrm{C}$ rats were not. Of the rats that showed high susceptibility to aDLS dopamine receptor blockade at baseline (a $>75 \%$ decrease in alcohol-seeking performance), $100 \%$ of those subsequently identified as compulsive 
maintained this susceptibility when seeking alcohol after the punishment stage (Test 3). Only $29 \%$ of rats that would be classified as I or NC were later susceptible to aDLS dopamine receptor blockade following punishment. The disengagement of aDLS control over drug seeking observed in NC or I rats thereby accounts for the lack of a relationship between aDLS susceptibility at baseline (Test 2) and at the later Tests $3\left(R^{2}=0.025, p=0.4\right)$ and $3 \mathrm{~A}\left(R^{2}=0.069, p=0.19\right)$.

This selective effect in $C$ rats cannot be attributable to rate dependency because of the following: (1) when comparing the influence on seeking responses of bilateral infusions of $5 \mu \mathrm{g} /$ side $\alpha$-flupenthixol into the aDLS as a percentage reduction from baseline at Tests 2 and 3, the effect of $\alpha$-flupenthixol was similar across these conditions (test: $F_{(1,23)}=2.22, p=$ not significant, $\mathrm{p} \eta^{2}=0.088$; compulsivity: $F_{(2,23)}=1.97, \mathrm{~ns}, \mathrm{p} \eta^{2}=0.146$; test $\times$ compulsivity interaction: $F_{(2,23)}=2.76, p=$ not significant, $\mathrm{p} \eta^{2}=0.194$; Fig. $\left.3 F\right)$, and if the effect was rate dependent, then the same decrement in responding would not have been seen between these conditions; and (2) the alcohol-seeking performance of $C$ rats still decreased following intra-aDLS infusions of $\alpha$-flupenthixol when tested in the absence of punishment under extinction conditions (Fig. $3 G, H)$, with a level of responding that was similar to that of I and NC rats under punishment conditions (Fig. $3 E$ ). Thus, insensitivity to this manipulation in I and NC rats under punishment is not due to a floor effect. Further, at baseline all rats do not equally rely on the aDLS despite engaging in drug seeking at similar rates.

The differential susceptibility to aDLS dopamine receptor blockade that emerged in $\mathrm{C}$ rats under punishment persisted after cessation of the punishment contingency, thereby indicating that their compulsive phenotype results from a rigid engagement of aDLS dopamine-dependent control over behavior (Fig. 3G,H). Thus, after several baseline sessions under the seeking-taking task in the absence of punishment, the reliance of postpunishment alcohol seeking on aDLS dopamine was assessed by bilateral infusion of the $10 \mu \mathrm{g} /$ infusion dose of $\alpha$-flupenthixol under extinction. This DA receptor blockade only reduced established seeking behavior in $\mathrm{C}$ rats (main effect of dose: $F_{(1,23)}=10.93$, $p=0.003, \mathrm{p} \eta^{2}=0.32$; compulsivity: $F_{(2,23)}=14.54, p=0.0001$, $\mathrm{p} \eta^{2}=0.56$; dose $\times$ compulsivity interaction: $F_{(2,23)}=4.77, p=$ $\left.0.019, \mathrm{p}^{2}=0.29\right)$. Post hoc analyses revealed that $\mathrm{C}$ rats decreased their alcohol seeking, whereas $\mathrm{NC}$ and I rats did not ( $p$ values $<0.001$; Fig. $3 G)$.

Because responding in extinction decreases over time during the session, reflecting the learning of a new contingency (i.e., response-no reinforcement) later on in the test session, seeking responses over the $15 \mathrm{~min}$ challenge session were analyzed in 5 min blocks. The selective effect of aDLS dopamine receptor blockade in $\mathrm{C}$ rats was confirmed in each block (main effect of dose: $F_{(1,46)}=12.65, p=0.002, \mathrm{p} \eta^{2}=0.36$; compulsivity: $F_{(2,23)}=14.54, p<0.001, \mathrm{p} \eta^{2}=0.56$; block: $F_{(2,46)}=73.22, p<$ $0.001, \mathrm{p} \eta^{2}=0.76$; dose $\times$ compulsivity interaction: $F_{(2,46)}=$ 4.24, $p=0.027, \mathrm{p} \eta^{2}=0.27$; dose $\times$ compulsivity $\times$ block interaction: $\left.F_{(4,46)}=4.90, p=0.002, \mathrm{p} \eta^{2}=0.30\right)$, indicating that these $C$ rat-specific effects did not reflect a differential influence of aDLS dopamine receptor blockade on learning. (Fig. $3 H$ ).
The differences observed among C, I, and NC rats were not attributable to an initial differential propensity to drink when alcohol was freely available under the two-bottle choice before the introduction of instrumental contingencies. Thus, C, I, and $\mathrm{NC}$ rats all displayed the $\mathrm{P}$ rat phenotype as they all equally increased their alcohol intake (in grams per kilogram) and alcohol preference over water (percentage) over the 12 sessions of intermittent access, reaching $6.54 \pm 0.19 \mathrm{~g} / \mathrm{kg} / 24 \mathrm{~h}$ (main effect of session: $F_{(11,253)}=22.75, p=0.0001, \mathrm{p}^{2}=0.50$; compulsivity: $F_{(2,23)}=0.28, p=$ not significant; session $\times$ compulsivity interaction: $F_{(22,253)}=0.37, p=$ not significant) and $93 \pm 1.12 \%$ preference (main effect of session: $F_{(11,253)}=32.87, p=0.0001$, $\mathrm{p} \eta^{2}=0.59$; compulsivity: $F_{(2,23)}=0.47, p=$ not significant; and session $\times$ compulsivity interaction: $F_{(22,253)}=0.29, p=$ not significant) over the last three sessions, respectively (Fig. 4). This observation replicates our earlier finding that the propensity to drink alcohol does not predict the transition to compulsive alcohol-seeking behavior (Giuliano et al., 2018).

The differences observed among C, I, and NC rats also were not attributable to a differential propensity to acquire instrumental responding for alcohol (main effect of session: $F_{(3,69)}=0.52$, $p=$ not significant, $\mathrm{p} \eta^{2}=0.022$; group: $F_{(2,23)}=0.38, p=$ not significant, $\mathrm{p} \eta^{2}=0.032$; group $\times$ session interaction: $F_{(6,69)}=$ $0.39, p=$ not significant, $\mathrm{p} \eta^{2}=0.033$; Fig. $5 A$ ), which, like the taking responses shown previously in this study, never devolved to aDLS dopamine-dependent control, regardless of the group. Thus, instrumental responding for alcohol under continuous reinforcement was not influenced by bilateral aDLS dopamine receptor blockade in $\mathrm{C}, \mathrm{I}$, and $\mathrm{NC}$ rats (main effect of group: $F_{(2,23)}=0.71, p=$ not significant, $\mathrm{p} \eta^{2}=0.058$; dose: $F_{(3,69)}=$ $1.39, p=$ not significant, $\mathrm{p} \eta^{2}=0.057$; dose $\times$ group interaction: $F_{(6,69)}=0.90, p=$ not significant, $\mathrm{p} \eta^{2}=0.073$; Fig. $\left.5 B\right)$. Moreover, aDLS dopamine receptor blockade did not affect taking responses either when alcohol seeking was well established (Test 2; Fig. 5C) or when compulsive (Test 3; Fig. 5D; main effect of dose: $F_{(3,69)}=0.39, p=$ not significant, $\mathrm{p} \eta^{2}=0.017$; and $F_{(3,69)}=1.69, p=$ not significant, $\mathrm{p} \eta^{2}=0.055$, respectively). Although the level of responding on the taking lever decreased between Test 2 and Test 3 and was of course higher in C rats (because of their punishment resistance), taking responses in C, I, and NC rats were equally unaffected by intra-aDLS 

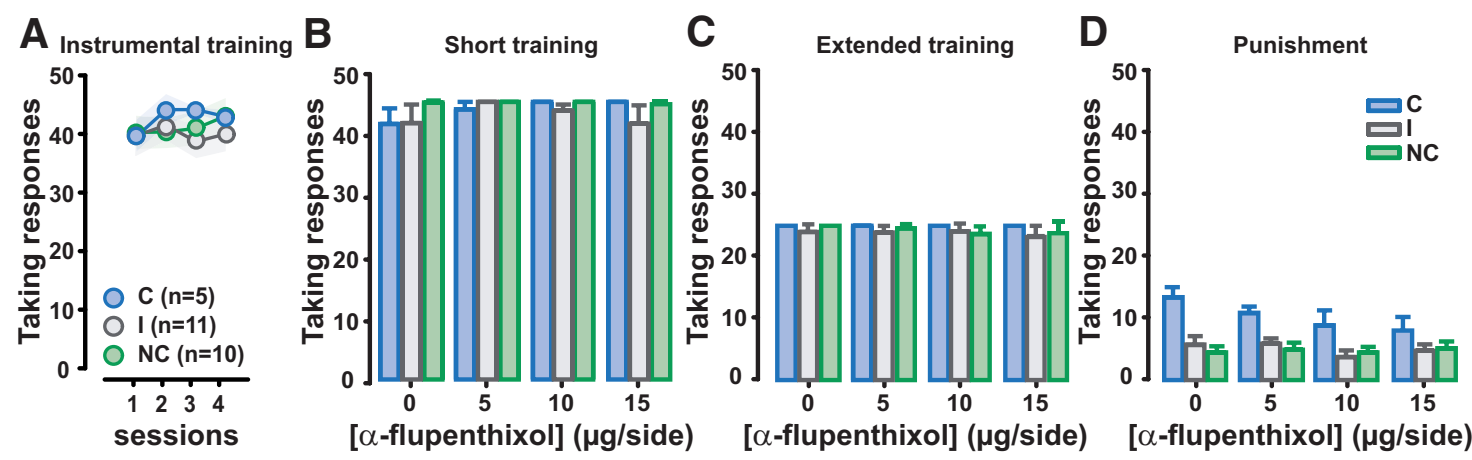

Figure 5. The vulnerability to compulsively seek alcohol is not predicted by the propensity to acquire instrumental responding for alcohol. $A$, C rats $(n=5$; blue dots), I rats ( $n=11$; gray dots), and $\mathrm{NC}$ rats $(n=15$; green dots) did not differ in their acquisition of instrumental responding for alcohol over four daily sessions. $\boldsymbol{B}$ - $\boldsymbol{D}$, Their taking responses were never affected by aDLS dopamine receptor blockade with $\alpha$-flupenthixol $(0,5,10$, or $15 \mu \mathrm{g} /$ side) during the progression of the training, after short $(\boldsymbol{B})$ or extended training $(\boldsymbol{C})$, or under the threat of punishment $(\boldsymbol{D})$. Graphs show mean \pm SEM values.

$\alpha$-flupenthixol (main effect of compulsivity: $F_{(2,23)}=13.57, p=$ 0.0001, $\mathrm{p} \eta^{2}=0.54$; Sidak's post hoc comparisons: C vs NC, $p<$ 0.001; C vs I, $p<0.01$; dose: $F_{(3,69)}=1.61, p=$ not significant, $\mathrm{p} \eta^{2}=0.065$; dose $\times$ compulsivity interaction: $F_{(6,69)}=0.72, p=$ not significant, $\mathrm{p} \eta^{2}=0.059$; main effect of test: $F_{(1,23)}=1104.59$, $p=0.0001 ; \mathrm{p} \eta^{2}=0.98$; test $\times$ dose: $F_{(3,69)}=0.77, p=$ not significant, $\mathrm{p} \eta^{2}=0.012$; test $\times$ compulsivity: $F_{(2,69)}=8.40, p=$ not significant, $\mathrm{p} \eta^{2}=0.42$; test $\times$ dose $\times$ compulsivity interactions: $F_{(6,69)}=1.59, p=$ not significant; $\mathrm{p} \eta^{2}=0.12$; Fig. $\left.5 C, D\right)$.

\section{Discussion}

The results of this study showed the following: (1) instrumental alcohol-seeking, but not alcohol-taking, responses became reliant on aDLS dopamine-dependent mechanisms in a subpopulation of $\mathrm{P}$ rats; (2) individual variability in the degree of susceptibility to aDLS dopamine receptor antagonism predicted the vulnerability to persist in seeking alcohol despite the risk of punishment; and (3) this compulsive alcohol-seeking behavior was associated with an inability to disengage aDLS dopaminedependent control over seeking responses in the face of punishment.

$P$ rats were used here because they show the following prerequisites for measuring the transition to compulsive alcoholseeking behavior: (1) they readily drink alcohol in excess of $5 \mathrm{~g}$ of alcohol $/ \mathrm{kg}$ body weight/d and spontaneously prefer alcohol over water; (2) based on our earlier work, they readily respond instrumentally under the control of alcohol-associated conditioned stimuli for the opportunity to drink alcohol (Giuliano et al., 2015); and (3) despite their strong preference for and propensity to drink alcohol, only a subgroup of these P rats eventually developed compulsive (punishment-resistant) alcohol-seeking behavior (Giuliano et al., 2018). Hence, here we sought to investigate the underlying neural mechanisms of this individual vulnerability. The behavioral procedure used spatially and temporally dissociates alcohol seeking from taking responses that are, respectively, distal and proximal to consummatory drinking behavior. As previously shown for food seeking and taking behavior (Balleine et al., 1995; Balleine, 2005), this procedure provides a way to interrogate and dissociate the neural and psychological mechanisms underlying drug-seeking and drug-taking responses (Everitt et al., 2018) as the compulsive seeking characteristic of addiction develops over time (Ostlund and Balleine, 2008; Zapata et al., 2010; Chen et al., 2013; Giuliano et al., 2018). Under these conditions, only seeking responses in the seeking-taking chain became dependent on aDLS dopamine, even though the perfor- mance of both seeking and taking responses required the same motor skill of lever pressing.

Earlier studies have shown that seeking and taking responses in instrumental chains depend on distinct psychological and neural mechanisms (Balleine et al., 1995; Olmstead et al., 2001; Pelloux et al., 2007). Thus, after a prolonged history of responding for cocaine or alcohol, seeking responses become stimulusresponse habits in that they eventually resist reinforcer devaluation or contingency degradation (Dickinson et al., 2002; Zapata et al., 2010; Corbit et al., 2012), which in the case of cocaine coincides with these responses becoming dependent on the aDLS (Zapata et al., 2010). Responding for alcohol similarly becomes resistant to reinforcer devaluation (Corbit et al., 2012) and dependent on aDLS dopamine and glutamate mechanisms (Möykkynen et al., 2003; Corbit and Janak, 2016).

The present data extend these observations by clarifying the distinction between habits and skills that have been conflated by some authors dismissive of the importance of these transitions from actions to habits and from ventral and dorsomedial striatum to aDLS control (Berridge and Robinson, 2016; Singer et al., 2018). While there is an obvious relationship between habits and skills (Graybiel and Grafton, 2015; Robbins and Costa, 2017), for example, both depend upon plasticity in the DLS, they also differ: skills refer to the qualitative and quantitative nature of the performance of a specific behavior (e.g., lever pressing, lacing one's shoes), whereas habits are underpinned by stimulus-response associations that govern the initiation of a behavioral sequence distal to and independent of the value of the goal (Adams and Dickinson, 1981; Balleine et al., 1995; Everitt and Robbins, 2005; Robbins and Costa, 2017; Malvaez and Wassum, 2018). Therefore, aDLS-dependent seeking habits may encompass the motor skill of lever pressing that may retain its goal directedness and lack of dependence on the DLS, as the present data show.

While it has been shown that instrumental responding on a single lever for orally administered alcohol or cocaine becomes habitual (Dickinson et al., 2002; Miles et al., 2003), as well as dependent on the aDLS (Corbit et al., 2012) more rapidly than highly palatable natural reinforcers, such as sucrose (Miles et al., 2003), the present study further reveals that this transition to aDLS control occurs only for seeking, and not for taking, responses under a chained reinforcement schedule that is designed to operationalize the sequence of distinctive foraging versus taking alcohol responses in humans. 
This dissociation showing that foraging responses that are more distal to the outcome are more likely to become dependent on the aDLS also indicates that this cannot be attributable solely to a difference in the reinforcement contingencies associated with the two responses, which can bias the control over behavior between goal-directed mechanisms or habits, even in the same individual on the same day (Gremel and Costa, 2013). Seeking responses in the chained schedule are never reinforced directly by presentation of the outcome, but instead result in the availability of the taking lever that therefore also acts as an occasion setter (Balleine et al., 1995) for the compound consummatory response sequence of a taking lever press, magazine approach, and alcohol drinking. In the case of intravenous cocaine, the taking response itself can be viewed as a consummatory response, since its outcome is solely the primary pharmacological effect of intravenously infused cocaine in the absence of gustatory cues or ingestion of the reinforcer.

A similar functional recruitment of aDLS dopamine in the control over drug seeking is seen in rats trained to respond over prolonged periods of time for cocaine (Ito et al., 2002; Vanderschuren et al., 2005; Willuhn et al., 2012) or heroin (Hodebourg et al., 2018) under second-order schedules in which conditioned reinforcers mediate delays to reinforcement (Arroyo et al., 1998). This is consistent with demonstrations in humans that drug cueelicited anticipatory responses such as craving are associated with activation of, and dopamine release in, the DLS (Garavan et al., 2000; Volkow et al., 2006; Vollstädt-Klein et al., 2010), the magnitude of which seems to be the best predictor of the subsequent propensity to relapse (Zilverstand et al., 2018).

Building on these data together with the recent demonstration that DLS dopamine release is increased by presentation of drugpaired cues in recreational cocaine users (Cox et al., 2017), the present results show that individual variability in aDLS dopaminedependent control over behavior actually predicts the vulnerability subsequently to develop compulsive alcohol seeking. Thus, despite a similar history of alcohol drinking and alcohol seeking, only a subset of rats became susceptible to intra-aDLS dopamine receptor blockade, and it was only and specifically a subset of these individuals that later developed compulsive alcohol seeking.

To our knowledge, this is the first demonstration that devolved control over drug seeking to aDLS dopamine transmission is a gateway to the development of compulsive drug seeking, which is a key feature of addictive behavior (American Psychiatric Association, 2013). Furthermore, the results show both that the magnitude of the decrease in seeking responses following aDLS dopamine receptor blockade predicts the subsequent transition to compulsivity and that the compulsive nature of alcohol seeking in vulnerable rats is associated with an inability to disengage aDLS control over behavior when faced with negative outcomes. The results also indicate that it is not the speed at which aDLS dopaminergic processes are recruited in a particular individual that is important, as previously suggested by computational models of basal ganglia function (Piray et al., 2010). For example, impulsive rats are especially likely to develop compulsive cocaine self-administration but are slower, not faster, in engaging the aDLS (Murray et al., 2014). Instead, the maladaptive nature of drug seeking in those individuals that become compulsive lies in the rigidity of these aDLS dopamine-dependent habits.

This rigid reliance of alcohol seeking on aDLS dopamine in compulsive rats is seen not only when seeking responses are made under the threat of punishment (Jonkman et al., 2012), but in the present study also several sessions after the termination of punishment, at a time when noncompulsive and intermediate rats remained as unresponsive to aDLS dopamine receptor blockade as when under the threat of punishment. This observation strongly suggests that resilient rats had either not engaged aDLS dopamine-dependent control over alcohol-seeking responses or were able to disengage this mechanism once seeking responses had been punished, as revealed in the data of noncompulsive and intermediate rats, respectively.

These results tested and support the hypothesis that engagement of the aDLS in the control over seeking behavior, a striatal region strongly associated with the consolidation and performance of stimulus-response habits (Yin et al., 2004; Zapata et al., 2010; Corbit et al., 2012), is predictive of the emergence of compulsive drug seeking. However, a purported recent test of this hypothesis in rats seeking cocaine came to a different conclusion (Singer et al., 2018), but the apparent discrepancy may readily be accounted for. First, the proposition tested in this study - that habits are necessary for addiction-like behavior-was solely that of the authors and has not, to our knowledge, been proposed previously. Rather, we have hypothesized that addictive behavior is characterized by compulsive drug-seeking habits (i.e., the focus is on the seeking of, or foraging for, drugs; Everitt and Robbins, 2005). Thus, in their ingenious puzzle-solving seeking-taking task, the sensitivity of seeking responses to punishment was never actually assessed by Singer et al. (2018), thereby failing to test the hypothesis. Instead, having shown that seeking responses were not affected by aDLS dopamine receptor blockade, the authors then chose to punish a completely different nose-poke taking response in a version of the three-criteria addiction procedure (Deroche-Gamonet et al., 2004). It has never been claimed or shown that taking responses under a low ratio schedule of reinforcement in this procedure become habitual, or under aDLS control, or that this is required for compulsivity. Indeed, we show here that taking responses remain completely insensitive to aDLS dopamine receptor blockade in contrast to the susceptibility of more distal seeking responses in the chained foraging sequence, even in compulsive animals.

Together, these results establish that not all individuals exposed to alcohol eventually develop aDLS dopamine-dependent alcohol-seeking habits and that the rigidity of the reliance of alcohol-seeking, but not alcohol-taking, responses on these aDLS mechanisms predicts and underlies the individual vulnerability to subsequently develop compulsivity. This observation is consistent with the evidence that cue-elicited dorsal striatal dopamine release associated with craving in humans is the best predictor of relapse and suggests that targeting inflexible seeking, rather than consummatory, responses may offer a therapeutic strategy to promote abstinence and prevent relapse.

\section{References}

Adams CD, Dickinson A (1981) Instrumental responding following reinforcer devaluation. Q J Exp Psychol B 33:109-121. CrossRef

American Psychiatric Association (2013) Diagnostic and statistical manual of mental disorders, Ed 5. Washington, DC: American Psychiatric Association Publishing.

Anthony JC, Warner LA, Kessler RC (1994) Comparative epidemiology of dependence on tobacco, alcohol, controlled substances, and inhalants: basic findings from the National Comorbidity Survey. Exp Clin Psychopharmacol 2:244-268. CrossRef

Arroyo M, Markou A, Robbins TW, Everitt BJ (1998) Acquisition, maintenance and reinstatement of intravenous cocaine self-administration under a second-order schedule of reinforcement in rats: effects of conditioned cues and continuous access to cocaine. Psychopharmacology (Berl) 140:331-344. CrossRef Medline

Balleine BW (2005) Neural bases of food-seeking: affect, arousal and reward 
in corticostriatolimbic circuits. Physiol Behav 86:717-730. CrossRef Medline

Balleine BW, Garner C, Gonzalez F, Dickinson A (1995) Motivational control of heterogeneous instrumental chains. J Exp Psychol Anim Behav Process 21:203-217. CrossRef

Belin D, Everitt BJ (2008) Cocaine seeking habits depend upon dopaminedependent serial connectivity linking the ventral with the dorsal striatum. Neuron 57:432-441. CrossRef Medline

Belin D, Belin-Rauscent A, Murray JE, Everitt BJ (2013) Addiction: failure of control over maladaptive incentive habits. Curr Opin Neurobiol 23: 564-572. CrossRef Medline

Bell RL, Rodd ZA, Lumeng L, Murphy JM, McBride WJ (2006) The alcoholpreferring $P$ rat and animal models of excessive alcohol drinking. Addict Biol 11:270-288. CrossRef Medline

Berridge KC, Robinson TE (2016) Liking, wanting, and the incentivesensitization theory of addiction. Am Psychol 71:670-679. CrossRef Medline

Besson M, Pelloux Y, Dilleen R, Theobald DE, Lyon A, Belin-Rauscent A, Robbins TW, Dalley JW, Everitt BJ, Belin D (2013) Cocaine modulation of frontostriatal expression of Zif268, D2, and 5-HT2c receptors in high and low impulsive rats. Neuropsychopharmacology 38:1963-1973. CrossRef Medline

Boileau I, Dagher A, Leyton M, Welfeld K, Booij L, Diksic M, Benkelfat C (2007) Conditioned dopamine release in humans: a positron emission tomography $\left[{ }^{11} \mathrm{C}\right]$ raclopride study with amphetamine. J Neurosci 27 : 3998-4003. CrossRef Medline

Cardinal RN, Aitken MR (2010) Whisker: a client-server high-performance multimedia research control system. Behav Res Methods 42:1059-1071. CrossRef Medline

Chen BT, Yau HJ, Hatch C, Kusumoto-Yoshida I, Cho SL, Hopf FW, Bonci A (2013) Rescuing cocaine-induced prefrontal cortex hypoactivity prevents compulsive cocaine seeking. Nature 496:359-362. CrossRef Medline

Childress AR, Mozley PD, McElgin W, Fitzgerald J, Reivich M, O’Brien CP (1999) Limbic activation during cue-induced cocaine craving. Am J Psychiatry 156:11-18. CrossRef Medline

Corbit LH, Janak PH (2016) Habitual alcohol seeking: neural bases and possible relations to alcohol use disorders. Alcohol Clin Exp Res 40:13801389. CrossRef Medline

Corbit LH, Nie H, Janak PH (2012) Habitual alcohol seeking: time course and the contribution of subregions of the dorsal striatum. Biol Psychiatry 72:389-395. CrossRef Medline

Cox SML, Yau Y, Larcher K, Durand F, Kolivakis T, Delaney JS, Dagher A, Benkelfat C, Leyton M (2017) Cocaine cue-induced dopamine release in recreational cocaine users. Sci Rep 7:46665. CrossRef Medline

Daniel ML, Cocker PJ, Lacoste J, Mar AC, Houeto JL, Belin-Rauscent A, Belin D (2017) The anterior insula bidirectionally modulates cost-benefit decision-making on a rodent gambling task. Eur J Neurosci 46:26202628. CrossRef Medline

David SP, Munafò MR, Johansen-Berg H, Smith SM, Rogers RD, Matthews PM, Walton RT (2005) Ventral striatum/nucleus accumbens activation to smoking-related pictorial cues in smokers and nonsmokers: a functional magnetic resonance imaging study. Biol Psychiatry 58:488-494. CrossRef Medline

Deroche-Gamonet V, Belin D, Piazza PV (2004) Evidence for addiction-like behavior in the rat. Science 305:1014-1017. CrossRef Medline

Di Chiara G, Imperato A (1988) Drugs abused by humans preferentially increase synaptic dopamine concentrations in the mesolimbic system of freely moving rats. Proc Natl Acad Sci U S A 85:5274-5278. CrossRef Medline

Dickinson A, Wood N, Smith JW (2002) Alcohol seeking by rats: action or habit? Q J Exp Psychol B 55:331-348. CrossRef Medline

Everitt BJ, Robbins TW (2005) Neural systems of reinforcement for drug addiction: from actions to habits to compulsion. Nat Neurosci 8:14811489. CrossRef Medline

Everitt BJ, Robbins TW (2016) Drug addiction: updating actions to habits to compulsions ten years on. Annu Rev Psychol 67:23-50. CrossRef Medline

Everitt BJ, Giuliano C, Belin D (2018) Addictive behaviour in experimental animals: prospects for translation. Philos Trans R Soc Lond B Biol Sci 373:20170027. CrossRef Medline

Garavan H, Pankiewicz J, Bloom A, Cho JK, Sperry L, Ross TJ, Salmeron BJ,
Risinger R, Kelley D, Stein EA (2000) Cue-induced cocaine craving: neuroanatomical specificity for drug users and drug stimuli. Am J Psychiatry 157:1789-1798. CrossRef Medline

Giuliano C, Goodlett CR, Economidou D, García-Pardo MP, Belin D, Robbins TW, Bullmore ET, Everitt BJ (2015) The novel $\mu$-opioid receptor antagonist GSK1521498 decreases both alcohol seeking and drinking: evidence from a new preclinical model of alcohol seeking. Neuropsychopharmacology 40:2981-2992. CrossRef Medline

Giuliano C, Peña-Oliver Y, Goodlett CR, Cardinal RN, Robbins TW, Bullmore ET, Belin D, Everitt BJ (2018) Evidence for a long-lasting compulsive alcohol seeking phenotype in rats. Neuropsychopharmacology 43 : 728-738. CrossRef Medline

Graybiel AM, Grafton ST (2015) The striatum: where skills and habits meet. Cold Spring Harb Perspect Biol 7:a021691. CrossRef Medline

Gremel CM, Costa RM (2013) Orbitofrontal and striatal circuits dynamically encode the shift between goal-directed and habitual actions. Nat Commun 4:2264. CrossRef Medline

Hodebourg R, Murray JE, Fouyssac M, Puaud M, Everitt BJ, Belin D (2018) Heroin seeking becomes dependent on dorsal striatal dopaminergic mechanisms and can be decreased by $\mathrm{N}$-acetylcysteine. Eur J Neurosci. Advance online publication. Retrieved March 7, 2018. doi:10.1111/ ejn. 13894

Ito R, Dalley JW, Robbins TW, Everitt BJ (2002) Dopamine release in the dorsal striatum during cocaine-seeking behavior under the control of a drug-associated cue. J Neurosci 22:6247-6253. CrossRef Medline

Jonkman S, Pelloux Y, Everitt BJ (2012) Differential roles of the dorsolateral and midlateral striatum in punished cocaine seeking. J Neurosci 32: 4645-4650. CrossRef Medline

Letchworth SR, Nader MA, Smith HR, Friedman DP, Porrino LJ (2001) Progression of changes in dopamine transporter binding site density as a result of cocaine self-administration in rhesus monkeys. J Neurosci 21: 2799-2807. CrossRef Medline

Malvaez M, Wassum KM (2018) Regulation of habit formation in the dorsal striatum. Curr Opin Behav Sci 20:67-74. CrossRef Medline

Miles FJ, Everitt BJ, Dickinson A (2003) Oral cocaine seeking by rats: action or habit? Behav Neurosci 117:927-938. CrossRef Medline

Möykkynen T, Korpi ER, Lovinger DM (2003) Ethanol inhibits alpha-amino3-hydyroxy-5-methyl-4-isoxazolepropionic acid (AMPA) receptor function in central nervous system neurons by stabilizing desensitization. J Pharmacol Exp Ther 306:546-555. CrossRef Medline

Murray JE, Dilleen R, Pelloux Y, Economidou D, Dalley JW, Belin D, Everitt BJ (2014) Increased impulsivity retards the transition to dorsolateral striatal dopamine control of cocaine seeking. Biol Psychiatry 76:15-22. CrossRef Medline

Murray JE, Belin-Rauscent A, Simon M, Giuliano C, Benoit-Marand M, Everitt BJ, Belin D (2015) Basolateral and central amygdala differentially recruit and maintain dorsolateral striatum-dependent cocaineseeking habits. Nat Commun 6:10088. CrossRef Medline

Olmstead MC, Lafond MV, Everitt BJ, Dickinson A (2001) Cocaine seeking by rats is a goal-directed action. Behav Neurosci 115:394-402. CrossRef Medline

Ostlund SB, Balleine BW (2008) On habits and addiction: an associative analysis of compulsive drug seeking. Drug Discov Today Dis Models 5:235-245. CrossRef Medline

Pelloux Y, Everitt BJ, Dickinson A (2007) Compulsive drug seeking by rats under punishment: effects of drug taking history. Psychopharmacology (Berl) 194:127-137. CrossRef Medline

Piray P, Keramati MM, Dezfouli A, Lucas C, Mokri A (2010) Individual differences in nucleus accumbens dopamine receptors predict development of addiction-like behavior: a computational approach. Neural Comput 22:2334-2368. CrossRef Medline

Porrino LJ, Lyons D, Smith HR, Daunais JB, Nader MA (2004) Cocaine self-administration produces a progressive involvement of limbic, association, and sensorimotor striatal domains. J Neurosci 24:3554-3562. CrossRef Medline

Porrino LJ, Smith HR, Nader MA, Beveridge TJ (2007) The effects of cocaine: a shifting target over the course of addiction. Prog Neuropsychopharmacol Biol Psychiatry 31:1593-1600. CrossRef Medline

Robbins TW, Costa RM (2017) Habits. Curr Biol 27:R1200-R1206. CrossRef Medline

Singer BF, Fadanelli M, Kawa AB, Robinson TE (2018) Are cocaine-seeking 
"habits" necessary for the development of addiction-like behavior in rats? J Neurosci 38:60-73. CrossRef Medline

Spoelder M, Hesseling P, Styles M, Baars AM, Lozeman-van't Klooster JG, Lesscher HM, Vanderschuren LJ (2017) Dopaminergic neurotransmission in ventral and dorsal striatum differentially modulates alcohol reinforcement. Eur J Neurosci 45:147-158. CrossRef Medline

Vanderschuren LJ, Di Ciano P, Everitt BJ (2005) Involvement of the dorsal striatum in cue-controlled cocaine seeking. J Neurosci 25:8665-8670. CrossRef Medline

Volkow ND, Wang GJ, Telang F, Fowler JS, Logan J, Childress AR, Jayne M, Ma Y, Wong C (2006) Cocaine cues and dopamine in dorsal striatum: mechanism of craving in cocaine addiction. J Neurosci 26:6583-6588. CrossRef Medline

Vollstädt-Klein S, Wichert S, Rabinstein J, Bühler M, Klein O, Ende G, Hermann D, Mann K (2010) Initial, habitual and compulsive alcohol use is characterized by a shift of cue processing from ventral to dorsal striatum. Addiction 105:1741-1749. CrossRef Medline
Willuhn I, Burgeno LM, Everitt BJ, Phillips PE (2012) Hierarchical recruitment of phasic dopamine signaling in the striatum during the progression of cocaine use. Proc Natl Acad Sci U S A 109:20703-20708. CrossRef Medline

Yin HH, Knowlton BJ, Balleine BW (2004) Lesions of dorsolateral striatum preserve outcome expectancy but disrupt habit formation in instrumental learning. Eur J Neurosci 19:181-189. CrossRef Medline

Zapata A, Minney VL, Shippenberg TS (2010) Shift from goal-directed to habitual cocaine seeking after prolonged experience in rats. J Neurosci 30:15457-15463. CrossRef Medline

Zijlstra F, Veltman DJ, Booij J, van den Brink W, Franken IH (2009) Neurobiological substrates of cue-elicited craving and anhedonia in recently abstinent opioid-dependent males. Drug Alcohol Depend 99:183-192. CrossRef Medline

Zilverstand A, Huang AS, Alia-Klein N, Goldstein RZ (2018) Neuroimaging impaired response inhibition and salience attribution in human drug addiction: a systematic review. Neuron 98:886-903. CrossRef Medline 